\title{
Recovery of Potassium from Incineration Ash of Chicken Dropping (IACD) by Sulphuric Acid Leaching Followed by Adsorption Using Orange Waste Gel
}

\author{
Hari Paudyal $^{* 1,2}$ Katsutoshi Inoue $^{2}$, Bimala Pangeni ${ }^{2,3}$ \\ ${ }^{1}$ Central Department of Chemistry, Tribhuvan University, Kirtipur, Kathmandu, Nepal \\ ${ }^{2}$ Department of Applied Chemistry, Saga University, Honjo 1, Saga 840-8502, Japan \\ ${ }^{3}$ Department of Botany, Tri-Chandra Multiple Campus, Ghantaghar, Kathmandu, Nepal \\ *Corresponding E-mail: hpaudyal@cdctu.edu.np \\ (Received: September 12, 2020; Revised: January 19, 2021; \& Accepted: January 21, 2021)
}

\begin{abstract}
Two types of leaching solution namely; aqua-regia and $1 \mathrm{MH}_{2} \mathrm{SO}_{4}$ were investigated for the leaching of $\mathrm{K}(\mathrm{I})$ from incineration ash of chicken dropping (IACD), in this study. SOJR and Na(I)-SOJR adsorbents were prepared from orange juice residue for the adsorption of K(I) from IACD leached liquor, which was compared with READF-(PG) and 200CT resin. The characterization of IACD leaching was done in EDX and FTIR spectroscopic techniques. Aqua-regia solution completely dissolved IACD and all the adsorbents. One molar sulphuric acid $\left(1 \mathrm{MH}_{2} \mathrm{SO}_{4}\right)$ solution was optimized for effective leaching of $\mathrm{K}(\mathrm{I})$ from the IACD sample. SOJR, $\mathrm{Na}(\mathrm{I})-\mathrm{SOJR}$, and $200 \mathrm{CT}$ adsorbed $\mathrm{K}(\mathrm{I})$ from leached liquor whereas $\mathrm{K}(\mathrm{I})$ was insignificantly adsorbed onto READF-(PG). The desorption of adsorbed $\mathrm{K}(\mathrm{I})$ could be successfully done by $\mathrm{H}_{2} \mathrm{SO}_{4}$ solution for recovery and adsorbent regeneration for further usage. From comparisons, $\mathrm{Na}(\mathrm{I})-\mathrm{SOJR}$ investigated in this study was found to be equally effective with a commercially available cation exchanger (200CT resin). Therefore, a new method of $\mathrm{H}_{2} \mathrm{SO}_{4}$ leaching of IACD followed by adsorption using $\mathrm{Na}(\mathrm{I})-\mathrm{SOJR}$ investigated in this work can be an economic, environmentally benign, and promising technique for the recovery of $\mathrm{K}(\mathrm{I})$ ion from leach liquor of IACD.
\end{abstract}

Keywords: IACD leaching, aqua-regia solution, sulphuric acid solution, K(I) ion, adsorptive recovery

\section{Introduction}

The manure of poultry and animals is widely applied to agricultural lands as a source of potassium, phosphorus, and nitrogen to improve soil fertility and increase crop production [1,2]. Nowadays, poultry farming is one of the popularly used agricultural activities all around the world including Nepal. The numbers of poultry farmers are increasing day by day and poultry farming is becoming a potential source of income due to the consumption of huge quantities of chicken meats and eggs all around the world. The poultry dropping is rich in potassium, nitrogen, phosphorus, calcium, and other useful minerals which are essential components for the growth and development of the plants [3,4]. Although chicken dropping is rich in various essential nutrients for the plant, however, the farmers dislike its application directly in their cropland because of unpleasant smell or bad order. The majority of these chicken dropping is used as manure after composting with waste biomass such as rice straw, rice husk, wasted leaves of plants, etc, or for direct application to croplands after drying and de-ordering.

From the scientific point of view, nitrogen $(\mathrm{N})$, potassium $(\mathrm{K})$, and phosphorus $(\mathrm{P})$ are recommended to be separately supplied on agricultural lands according to the growing requirement of each plant instead of supplying all components together [4]. The application of the right amount of nutrients potentially improves the health of plants and finally increases crop production. Because of this reason, it is necessary to recover $\mathrm{P}, \mathrm{K}$, and $\mathrm{N}$ separately from chicken dropping. The incineration technique is one of the common methods used to reduce the volume of chicken dropping worldwide [5-7]. The organic components of chicken dropping are completely gasified into $\mathrm{H}_{2}, \mathrm{CH}_{4}, \mathrm{CO}_{2}$, and $\mathrm{C}_{2} \mathrm{H}_{4}$ [8]. The chicken dropping is not only composed of organic matter 
but also inorganic matter, water, and gas, resulting in the production of not only gas but also solid and liquid byproducts during incineration. The organic gas generated during incineration is used as fuel gas whereas incineration ash of chicken dropping (IACD) remains as waste residue, which can be a potential source of potassium, phosphorus, and nitrogen after recovery.

In our previous study, phosphorus was recovered from IACD by leaching with a citric acid solution followed by adsorption using READF-(PG) resin [4]. The $\mathrm{P}$ exists in the forms of its oxoanions such as $\mathrm{H}_{2} \mathrm{PO}_{4}^{-}, \mathrm{HPO}_{4}^{2-}$ and $\mathrm{PO}_{4}^{3-}$ in leaching solution so that anion exchange resins such as READF-(PG) are effective to recover these anionic species from leached liquor but recovery of cationic species such as $\mathrm{Ca}(\mathrm{II}), \mathrm{Zn}(\mathrm{II}), \mathrm{K}(\mathrm{I})$, etc are quite difficult by anion exchange resins, which needs cation exchanger for its effective recovery. Potassium plays a very important role in cellular homeostasis, plant growth, and crop production [9-11]. The application of potassium fertilizer in cropland is increased every year. More than 40 million tons of potassium fertilizer are consumed in 2018 [10]. The major source of potassium in nature is potash minerals obtained from underground brine, carnallite $\left(\mathrm{KCl} \cdot \mathrm{MgCl}_{2} \cdot 6 \mathrm{H}_{2} \mathrm{O}\right)$, and seawater $[12,13]$. Therefore there is an urgent need to recover potassium from insoluble potash ore such as Biotite $\left(\mathrm{K}(\mathrm{Mg}, \mathrm{Fe})_{3} \mathrm{AlSi}_{3} \mathrm{O}_{10}(\mathrm{OH})_{2}\right)$, K-feldspar $\left(\mathrm{KAlSi}_{3} \mathrm{O}_{8}\right)$, and other potassium-rich waste material [14].

Potassium is one of the major components in IACD [4]. From our experience, the pectin enriched biomass of orange juice residue (OJR) after chemical modification was found to be effective for the adsorption of metal ions and recovery of phosphorus anion from aqueous solution [15-18]. In the present investigation, two types of natural cation exchangers namely SOJR and $\mathrm{Na}(\mathrm{I})$-SOJR were first prepared from waste biomass of OJR by simple chemical modification and employed to recover $\mathrm{K}(\mathrm{I})$ from leach liquor of IACD. The method involving the leaching of a metal ion such as K(I) from IACD by $\mathrm{H}_{2} \mathrm{SO}_{4}$ solution followed by adsorption using 200CT, SOJR, and $\mathrm{Na}(\mathrm{I})-\mathrm{SOJR}$. The performance of $\mathrm{K}(\mathrm{I})$ recovery by orange waste-based adsorbents were also compared with two types of commercially available ion exchange resin, namely READF-(PG) and 200CT, in this work.

\section{Materials and Methods Materials}

The sample of IACD employed in this study was supplied from NANGOKU-KOSAN Co. Ltd.,
Miyazaki, Japan, free of cost. The orange juice residue (OJR) used to prepare adsorbent for the recovery of potassium was donated by JA. Saga Beverage Co. Ltd., Japan. The sample of READF resin (READF(PG)) and 200CT resin were supplied from Nihon Kaisui Co. Ltd., Tokyo, Japan, and ORGANO Corporation, Tokyo, Japan, respectively.

\section{Chemicals and instrumentation}

In this work, the pure analytical grade chemicals purchased from Wako Chemical Co. Ltd., Japan were used directly without further purification. The $\mathrm{pH}$ of the solution was measured by a $\mathrm{pH}$ meter (HM-30R, TOA DKK Corp.). The existence of various elements in the IACD sample before and after leaching was measured by using an energy dispersive X-ray spectrometer (EDX, Shimadzu model, Rayny EDX$800 \mathrm{HS}$ ). The functional group changes in IACD by leaching reactions were measured by recording spectra using Fourier transform infrared spectrometer (FTIR, JASCO FTIR-410). The concentration of potassium was determined using an atomic absorption spectrophotometer (AAS, Shimadzu model AAS 6800) whereas other metal ions silicon (Si), magnesium $(\mathrm{Mg})$, calcium $(\mathrm{Ca})$, phosphorus $(\mathrm{P})$, aluminum $(\mathrm{Al})$, iron $(\mathrm{Fe})$, and zinc $(\mathrm{Zn})$ were measured by using inductively coupled plasma atomic emission spectroscopy (ICP-AES, Shimadzu model ICPS 8100).

\section{Total dissolution of IACD sample by aqua-regia solution}

A sample of IACD was completely dissolved in aqua regia and used to determine the total amounts of various elements as follows. One gram of IACD was mixed with aqua regia $(30 \mathrm{~mL})$ and stirred for $24 \mathrm{~h}$ at $30^{\circ} \mathrm{C}$ to ensure complete dissolution. Then, it was filtered and the concentration of $\mathrm{K}(\mathrm{I})$ was measured by AAS whereas the concentrations of $\mathrm{Mg}, \mathrm{Ca}, \mathrm{P}$, and $\mathrm{Si}$ were measured using ICP-AES. The leached amounts of various elements were calculated according to the following mass balance equations

$$
\mathrm{Q}_{\mathrm{L}}=\frac{\mathrm{L}_{\mathrm{C}} \times \mathrm{V}}{\mathrm{W}}
$$

where $\mathrm{L}_{\mathrm{C}}$ is the concentration $(\mathrm{mg} / \mathrm{L})$ of the target element leached using a citric acid solution, $\mathrm{W}$ is the weight (g) of IACD used for the total dissolution experiment and $\mathrm{V}$ is the volume of test solution in liter. A similar procedure was adopted for the complete dissolution of READF-(RG) resin in a previous study [19]. 
Leaching test of IACD by sulphuric acid solution

The leaching test of IACD was carried out by using a sulphuric acid solution. One gram of IACD and 30 $\mathrm{mL}$ of $1 \mathrm{MH}_{2} \mathrm{SO}_{4}$ and $\mathrm{H}_{2} \mathrm{SO}_{4}$ solution at $\mathrm{pH}$ ranging from 1 up to 5 . Then the mixtures were stirred for 24 $\mathrm{h}$ at $30^{\circ} \mathrm{C}$ at speed of $150 \mathrm{rpm}$. Then, solutions were filtered and the concentrations of potassium and other elements were measured by using ICP-AES and AAS. The percentage leaching ( $\% \mathrm{~L})$ of various elements was calculated according to the following equations.

$$
\% \mathrm{~L}=\frac{\mathrm{Q}_{\mathrm{SA}}}{\mathrm{Q}_{\mathrm{AQ}}} \times 100
$$

where $\mathrm{Q}_{\mathrm{SA}}$ and $\mathrm{Q}_{\mathrm{AQ}}$ are the leached amounts $(\mathrm{mg} / \mathrm{g}$ ) of the targeted elements using $\mathrm{H}_{2} \mathrm{SO}_{4}$ and aqua regia, respectively.

\section{Preparation of leached liquor of IACD}

For this, $3.34 \mathrm{~g}$ of IACD was mixed with $500 \mathrm{~mL}$ of $1 \mathrm{MH}_{2} \mathrm{SO}_{4}$ solution and stirred for $24 \mathrm{~h}$ at $30^{\circ} \mathrm{C}$ at speed of $150 \mathrm{rpm}$. Then the mixture was filtered by double filter paper and the filtrate was stored in a $1 \mathrm{~L}$ plastic bottle. The leaching solution obtained in this way is termed sulphuric acid leached liquor and abbreviated as SALL hereafter.

\section{Adsorbents for the recovery of $K(I)$ ion Preparation of SOJR and Na(I)-SOJR adsorbents} The saponified orange juice residue (SOJR) was prepared according to the procedure described in else ware only difference is that $0.1 \mathrm{M} \mathrm{NaCl}$ solution was used instead of multivalent metal ions solution as follows [16]. First of all $100 \mathrm{~g}$ of OJR was washed with distilled water then mixed with $4 \mathrm{~g}$ of $\mathrm{Ca}(\mathrm{OH})_{2}$ and pulverized into a fine powder with the help of juice mixture for 5 minutes. Then it was shacked for $24 \mathrm{~h}$ at $30^{\circ} \mathrm{C}$ to complete the saponification reaction of methyl ester part of orange pectin into carboxyl groups as shown in Scheme 1.

In addition to this, some pellet of $\mathrm{NaOH}$ ( 3 or 4) was also added to the reaction mixture to enhance the saponification reaction. After $24 \mathrm{~h}$, the solid-liquid separation was made by decantation followed by filtration several times until the $\mathrm{pH}$ of washing water became neutral and dried in an oven at $70^{\circ} \mathrm{C}$. The white material obtained in this way is the saponified product of orange juice residue and abbreviated as SOJR hereafter.

The SOJR was converted into $\mathrm{Na}(\mathrm{I})$-SOJR by loading $\mathrm{Na}(\mathrm{I})$ as follows. Since, the SOJR is $\mathrm{Ca}$ (II) salt of orange pectic acid i.e calcium pectate, which contains exchangeable $\mathrm{Ca}$ (II) ion, where loading reaction of cationic species such as metal ions occurs by cation exchange reaction with the release of calcium ion also shown in Scheme 1. The loading of $\mathrm{Na}(\mathrm{I})$ in saponified orange juice residue is similar to the adsorption of $\mathrm{Pb}(\mathrm{II}), \mathrm{Cd}(\mathrm{II}), \mathrm{Zn}(\mathrm{II})$, and $\mathrm{Fe}(\mathrm{III})$ onto saponified apple juice residue [19]. For this, five gram of SOJR was mixed with $500 \mathrm{~mL}$ of $0.1 \mathrm{M} \mathrm{NaCl}$ solution at $\mathrm{pH}$ 6.5 and stirred for $\mathrm{Na}(\mathrm{I})$ loading reaction. After $24 \mathrm{~h}$ shacking, it was washed several times with distilled water until neutral $\mathrm{pH}$ dried at $70^{\circ} \mathrm{C}$ for $24 \mathrm{~h}$. The final product obtained in this way is known as $\mathrm{Na}(\mathrm{I})$ loaded SOJR and abbreviated as $\mathrm{Na}(\mathrm{I})-\mathrm{SOJR}$ hereafter.

\section{Commercial ion exchange resins}

The 200CT resin is a sulphonic acid type cation exchange resin (structure a) containing exchangeable $\mathrm{Na}(\mathrm{I})$, where metal ions were absorbed by cation exchange reaction with $\mathrm{Na}(\mathrm{I})$ ion. READF-(PG) resin is produced by impregnating the micropores of ethylene vinyl alcohol (EVOH) beads with a $\mathrm{Zr}(\mathrm{IV})$ solution (structure b), followed by hydrolysis using an alkaline solution to form the fine powder of hydrated zirconium oxide $\left(\mathrm{Hy}-\mathrm{ZrO}_{2}\right)$ inside the pores.

Adsorption test of K(I) from leached liquor of IACD The recovery of potassium from leached liquors was carried out by using two types of cation exchanger SOJR and $\mathrm{Na}(\mathrm{I})$-SOJR prepared from orange juice residue and compared with commercially available READF-(PG) and 200CT resins. The adsorption test of potassium was performed batch-wise at different $\mathrm{pH}$ values ranging from 1 to 5 , where $15 \mathrm{mg}$ of

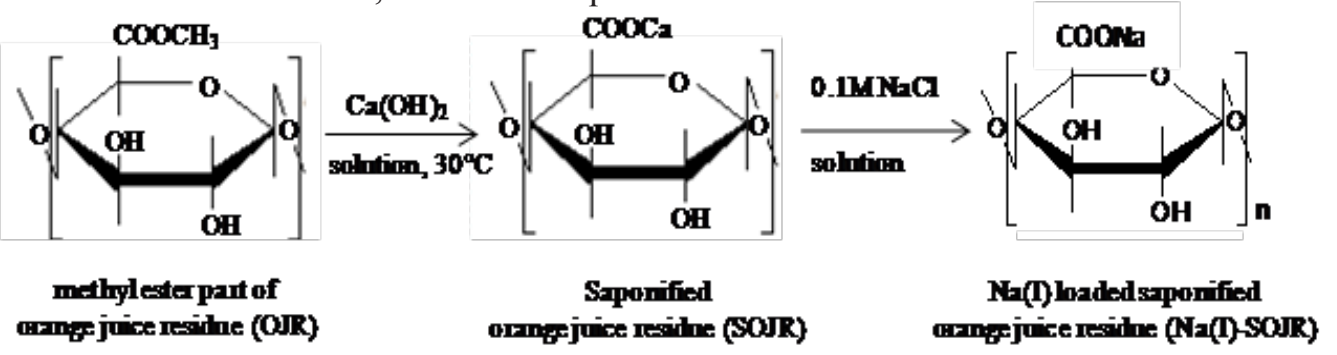

Scheme 1: Synthetic route of SOJR and Na(I)-SOJR from orange juice residue 


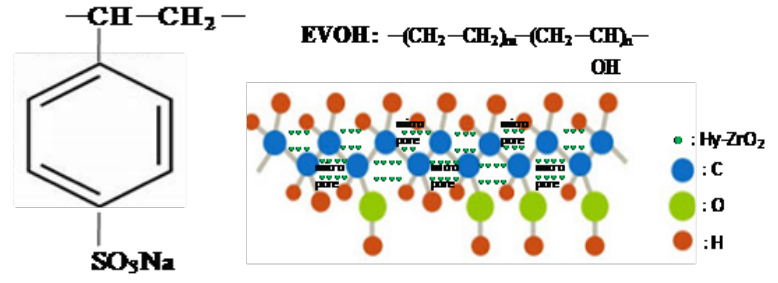

$\begin{array}{ll}\text { (a) Structure 200CT resin } & \text { (b) Structure READF-(PG) resin }\end{array}$

adsorbents were mixed with $10 \mathrm{~mL}$ of leached liquor followed by shaking for $24 \mathrm{~h}$. Then it was filtered and concentrations of potassium before and after adsorption were measured by atomic absorption spectrophotometer. The percentage removal of potassium from IACD leached liquor was calculated by using the following equation.

$$
\% A=\frac{C_{i}-C_{e}}{C_{\mathrm{i}}} \times 100
$$

where, $\mathrm{C}_{\mathrm{i}}$ and $\mathrm{C}_{\mathrm{e}}$ are the concentration of potassium $(\mathrm{mg} / \mathrm{L})$ before and after adsorption, respectively.

\section{Desorption of $\mathrm{K}(\mathrm{I})$ using $\mathrm{H}_{2} \mathrm{SO}_{4}(\mathrm{SA})$ solution}

It was observed from the results of a batch experiment that the $\mathrm{Na}(\mathrm{I})$-SOJR was equally effective with 200CT resin, sulphonic acid type commercial cation exchange resin containing exchangeable $\mathrm{Na}(\mathrm{I})$ ion, for the adsorption of $\mathrm{K}(\mathrm{I})$ from leached liquor of IACD in batch mode. Therefore, the desorption experiment was done only using $\mathrm{K}(\mathrm{I})$ adsorbed $\mathrm{Na}(\mathrm{I})$-SOJR using a varying concentration of sulphuric acid ranging from 0.005 to $1.5 \mathrm{M}$ at a solid-liquid ratio of $5 \mathrm{~g} / \mathrm{L}$ at $30^{\circ} \mathrm{C}$. After stirring $24 \mathrm{~h}$ at a speed of $150 \mathrm{rpm}$, the solid-liquid separation was done by filtration then the concentration of $\mathrm{K}(\mathrm{I})$ ion in the eluted solution was measured by using AAS. The \% desorption of K(I) was calculated according to the following relation.

$$
\% \mathrm{D}=\frac{\mathbf{D}_{\text {amount }}}{\mathrm{A}_{\text {amount }}} \times 100
$$

where and are the adsorbed and desorbed amount of K(I) $(\mathrm{mg} / \mathrm{g})$, respectively.

\section{Results and Discussion}

Evaluation of various elements in leached liquor of IACD The aqua-regia is one of the very strong leaching agents among the acidic solution. The leaching test using an aqua-regia solution shows that nearly the entire solid sample of IACD was dissolved in aquaregia solution after $24 \mathrm{~h}$ shaking. Therefore the total amount of elements that exist in the sample of IACD was determined by measuring the amounts of these elements leached using aqua-regia solution. Table 1 shows the amounts of various elements leached out using aqua--regia, and $1 \mathrm{MH}_{2} \mathrm{SO}_{4}$ solution. It is clear from the result of this table that $\mathrm{Zn}, \mathrm{Fe}, \mathrm{Al}$, and $\mathrm{Na}$ are in minor amounts whereas $\mathrm{K}, \mathrm{P}, \mathrm{Ca}, \mathrm{Mg}$, and $\mathrm{Si}$ have existed in major quantities in IACD. After leaching by $1 \mathrm{M} \mathrm{H}_{2} \mathrm{SO}_{4}$ solution, less than $50 \%$ of $\mathrm{P}, \mathrm{Ca}$, and $\mathrm{Si}$ was leached out whereas more than $95 \%$ of leaching was observed in the case of $\mathrm{Na}, \mathrm{K}, \mathrm{Al}$, and $\mathrm{Fe}$, which strongly suggest that $1 \mathrm{M} \mathrm{H}_{2} \mathrm{SO}_{4}$ solution can be employed as an effective leaching solution.

Table 1: Amount of various elements leached from IACD using aqua-regia, and $1 \mathrm{M} \mathrm{H}_{2} \mathrm{SO}_{4}$ solution

\begin{tabular}{lccc}
\hline Element & \multicolumn{3}{c}{$\begin{array}{c}\text { Leached amounts (mg/g) of various } \\
\text { elements from the IACD sample }\end{array}$} \\
\cline { 2 - 4 } & $\begin{array}{c}\text { Aqua-regia } \\
\text { leaching } \\
(\mathrm{mg} / \mathrm{g})\end{array}$ & $\begin{array}{c}\mathrm{H}_{2} \mathrm{SO}_{4} \\
\text { leaching } \\
(\mathrm{mg} / \mathrm{g})\end{array}$ & $\% \mathrm{~L}$ \\
\hline $\mathrm{Zn}$ & 2.43 & 1.79 & 73.66 \\
$\mathrm{Fe}$ & 4.39 & 4.4 & 98.86 \\
$\mathrm{Al}$ & 1.91 & 1.90 & 99.47 \\
$\mathrm{Si}$ & 10.69 & 4.30 & 40.22 \\
$\mathrm{Mg}$ & 43.91 & 29.11 & 66.29 \\
$\mathrm{Ca}$ & 126.76 & 62.23 & 49.09 \\
$\mathrm{P}$ & 91.57 & 41.01 & 44.78 \\
$\mathrm{~K}$ & $\mathbf{8 5 . 1 4}$ & $\mathbf{8 2 . 3 2}$ & $\mathbf{9 6 . 6 8}$ \\
$\mathrm{Na}$ & 1.97 & 1.94 & 98.47 \\
\hline
\end{tabular}

Spectroscopic characterizations by FTIR and EDX The dissolution of various functional groups in IACD after leaching with $1 \mathrm{MH}_{2} \mathrm{SO}_{4}$ was tested by comparing the FTIR spectra of IACD before and after leaching and the results are shown in Table 2. It is clear from the results of this table that the strong peak observed at around 3375 in the FTIR spectrum of IACD before leaching is due to the stretching vibration of $\mathrm{OH}$ groups. The peak at around 1417.87, 1116.65 , and $1079.97,1046.56 \mathrm{~cm}^{-1}$ are due to the stretching vibration of $\mathrm{C}-\mathrm{O}$ (calcite compounds), $\mathrm{P}-\mathrm{O}$ (oxides of phosphorus-rich compounds) and $\mathrm{P}=\mathrm{O}$ (different phosphate compounds), and C-O-C groups, respectively. After leaching with the $\mathrm{H}_{2} \mathrm{SO}_{4}$ solution, the peaks observed at around 1417.87, 1116.65, 1079.97 , and $621 \mathrm{~cm}^{-1}$ were completely disappeared which is attributed due to the leaching of different elements by breaking the chemical bond that exists in the various functional groups in IACD. The peak observed at $621 \mathrm{~cm}^{-1}$ which is due to $\mathrm{K}-\mathrm{O}$ stretching vibration in IACD was also disappeared after $\mathrm{H}_{2} \mathrm{SO}_{4}$ leaching suggesting that the leaching of potassium effectively occurred by $\mathrm{H}_{2} \mathrm{SO}_{4}$ solution. Further 
Table 2: FTIR spectra of IACD before and after $\mathrm{H}_{2} \mathrm{SO}_{4}$ leaching showing the variation of absorption frequencies of various functional groups

\begin{tabular}{lcc}
\hline \multirow{2}{*}{$\begin{array}{l}\text { Functional } \\
\text { groups }\end{array}$} & $\begin{array}{c}\text { Peaks observed at different absorption } \\
\text { frequencies }\left(\mathbf{c m}^{-1}\right)\end{array}$ & in FT-IR spectra \\
\cline { 2 - 3 } & $\begin{array}{c}\text { Before leaching } \\
\text { by } \mathrm{H}_{2} \mathrm{SO}_{4} \text { solution }\end{array}$ & $\begin{array}{c}\text { After leaching by } \\
\mathrm{H}_{2} \mathrm{SO}_{4} \text { solution }\end{array}$ \\
OH stretching & 3460.58 & 3460.87 \\
$\mathrm{C}-\mathrm{O}$ stretching & 1417.87 & - \\
$\mathrm{P}-\mathrm{O}$ stretching & 1116.65 & - \\
$\mathrm{P}=\mathrm{O}$ stretching & 1079.97 & - \\
$\mathrm{C}-\mathrm{O}-\mathrm{C}$ stretching & 1046.56 & 1059.42 \\
K-O stretching & 621.78 & - \\
\hline
\end{tabular}

evidence for the leaching of potassium and other elements will be confirmed by elemental analysis.

Fig. 1 shows the energy dispersive X-ray (EDX) spectra of IACD before and after $\mathrm{H}_{2} \mathrm{SO}_{4}$ leaching. EDX spectrum of IACD contains the peaks corresponding to carbon $(\mathrm{C}, 0.28 \mathrm{keV})$, oxygen $(\mathrm{O}, 0.32 \mathrm{keV})$, sodium $(\mathrm{Na}, 1.03 \mathrm{keV})$, magnesium $(\mathrm{Mg}, 1.26 \mathrm{keV})$, aluminum $(\mathrm{Al}, 1.48 \mathrm{keV})$, silicon $(\mathrm{Si}, 1.72 \mathrm{keV})$, phosphorus $(\mathrm{P}, 2.01 \mathrm{keV})$, sulphur $(\mathrm{S}, 2.32 \mathrm{keV})$, chlorine $(\mathrm{Cl}$, $2.62 \mathrm{keV})$, potassium $(\mathrm{K}, 3.32 \mathrm{keV})$, calcium $(\mathrm{Ca}$, 3.68 and $4.12 \mathrm{keV})$, manganese (Mn, $5.84 \mathrm{keV})$, iron $(\mathrm{Fe}, 6.41 \mathrm{keV})$, and zinc $(\mathrm{Zn}, 8.64 \mathrm{keV})$. The intensity of some elements such as $\mathrm{P}, \mathrm{Ca}$, and $\mathrm{K}$ were found to be higher than other elements indicating that these elements are the major elements in the IACD sample.

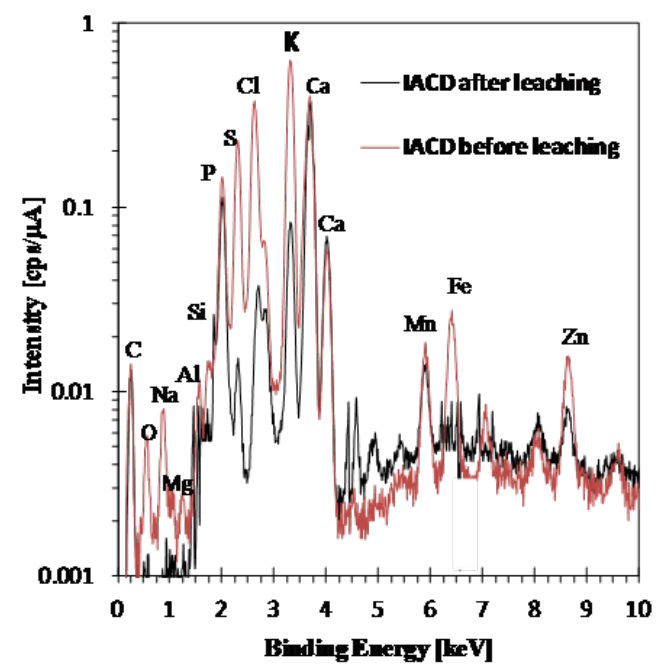

Figure 1: Energy dispersive X-ray (EDX) spectra of IACD before and after $\mathrm{H}_{2} \mathrm{SO}_{4}$ leaching showing the variation of intensities of various elements by leaching reaction

After leaching, the peak due to $\mathrm{O}, \mathrm{Na}$, and $\mathrm{Mg}$ were completely disappeared at binding energies values around $0.32,1.03$, and $1.26 \mathrm{keV}$, respectively. The intensities of peaks due to $\mathrm{Zn}, \mathrm{Fe}, \mathrm{Cl}$, and $\mathrm{P}$ at binding energies values around 8.64, 6.41, 2.62, and
$2.01 \mathrm{keV}$ were found to be greatly decreased after leaching reaction. The intensity of peak corresponds to $\mathrm{K}$ observed at binding energy around $5.84 \mathrm{keV}$ was $0.48 \mathrm{cps} / \mu \mathrm{A}$ in IACD, which was decreased to 0.08 $\mathrm{cps} / \mu \mathrm{A}$ after $\mathrm{H}_{2} \mathrm{SO}_{4}$ leaching. The result confirms the successful leaching of potassium from IACD during $\mathrm{H}_{2} \mathrm{SO}_{4}$ leaching.

\section{Optimization $\mathrm{H}_{2} \mathrm{SO}_{4}$ solution for IACD leaching}

The percentage leaching of different elements by using a varying concentration of $\mathrm{H}_{2} \mathrm{SO}_{4}(1 \mathrm{M}$ to $\mathrm{pH}$ 5 ) is shown in Fig. 2. From the result of this figure, it is clear that the leaching of $\mathrm{Mg}, \mathrm{Si}, \mathrm{P}, \mathrm{K}$, and $\mathrm{Ca}$ was found to be increased with increasing acid concentration. At a lower concentration of $\mathrm{H}_{2} \mathrm{SO}_{4}(\mathrm{pH}$ 5), the leaching of $\mathrm{Mg}, \mathrm{Si}, \mathrm{P}, \mathrm{K}$, and $\mathrm{Ca}$ is insignificant $(<5 \%)$ whereas maximum leaching was observed using $1 \mathrm{M} \mathrm{H}_{2} \mathrm{SO}_{4}$ for all the elements tested. The maximum leaching of $\mathrm{Mg}, \mathrm{P}, \mathrm{Si}$, and $\mathrm{Ca}$ was found to be $66.27,53.95,40.24$, and $62.23 \%$, respectively by using a $1 \mathrm{MH}_{2} \mathrm{SO}_{4}$ solution. The percentage leaching of $\mathrm{K}$ was only $4.94 \%$ at $\mathrm{pH} 5$ which was observed to be increased and reached $29.85 \%$ at $\mathrm{pH} 2$ whereas it was higher than $95 \%(96.68 \%)$ by using $1 \mathrm{MH}_{2} \mathrm{SO}_{4}$. The increase of potassium leaching efficiency while increasing the acid concentration is due to the acid concentration effect on increasing the $\mathrm{H}^{+}$activity that results in further dissolution [20,21].

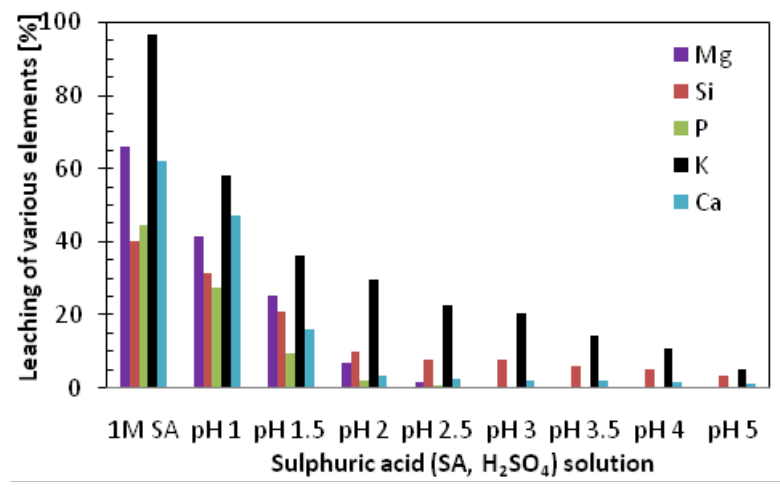

Figure 2: Leaching of various elements by varying the concentration of $\mathrm{H}_{2} \mathrm{SO}_{4}$ solution from IACD

The leaching of $\mathrm{K}$ was not significantly improved with a further increase in acid concentration (not higher than $97 \%$ even at $5 \mathrm{M} \mathrm{H}_{2} \mathrm{SO}_{4}$, not shown in the figure). Owing to these results, the $1 \mathrm{M} \mathrm{H}_{2} \mathrm{SO}_{4}$ solution is recommended for effective leaching for $\mathrm{K}$ (I) from IACD. By contrast, the insignificant or negligible leaching of all the elements including K(I) was observed in the case of using only distilled water as a leaching solution. 
To prepare the model sample of leach liquor of IACD, $3.34 \mathrm{~g}$ of dried IACD was dissolved in $500 \mathrm{~mL}$ of $1 \mathrm{M}$ $\mathrm{H}_{2} \mathrm{SO}_{4}$ taking account of the result shown in Fig. 2. The concentrations of all species present in this leach liquor were measured by ICP-AES as shown in table 1 in the earlier section. The recovery of $\mathrm{K}(\mathrm{I})$ ion was carried out by using this leach liquor which will be described in detail in section 3.4 below.

\section{Adsorptive recovery of potassium from leached liquor of IACD Adsorption of potassium onto different adsorbents} From the preliminary experiment, the adsorbents such as SOJR, Na(I)-SOJR, READF-(PG), and 200CT resin were completely dissolved in leached liquor prepared using aqua-regia solution so that it is difficult to recover $\mathrm{K}(\mathrm{I})$ from aqua-regia leached liquor of IACD by using these adsorbents. Therefore the leached liquor was prepared using a $1 \mathrm{MH}_{2} \mathrm{SO}_{4}$ solution for the recovery of $\mathrm{K}(\mathrm{I})$ in the subsequent experiment. The recovery of $\mathrm{K}(\mathrm{I})$ from sulphuric acid leach liquor (SALL) of IACD was carried out using SOJR, Na(I)-SOJR, READF-(PG), and 200CT resin, and the results obtained are shown in Fig. 3. It is clear from the result of this figure that the READF(PG), which is marketed for the removal of fluoride ion, was not effective for the removal of $\mathrm{K}(\mathrm{I})$ ion in all the tested $\mathrm{pH}$ ranging from 1-5. In an acidic medium, potassium exists as a cation, i.e., $\mathrm{K}^{+}$ion, which was hardly adsorbed onto the anion exchange site of READF-(PG) resin. The SOJR, Na(I)-SOJR, and 200CT resins effectively adsorb K(I) from leach liquor. The adsorption efficiency of $\mathrm{Na}(\mathrm{I})$-SOJR and 200CT resin were found to be higher than SOJR.

TheNa(I)-SOJR and200CTresin contain exchangeable $\mathrm{Na}$ (I) ions whereas SOJR has exchangeable $\mathrm{Ca}$ (II) for cation exchange reaction with $\mathrm{K}(\mathrm{I})$ exist in

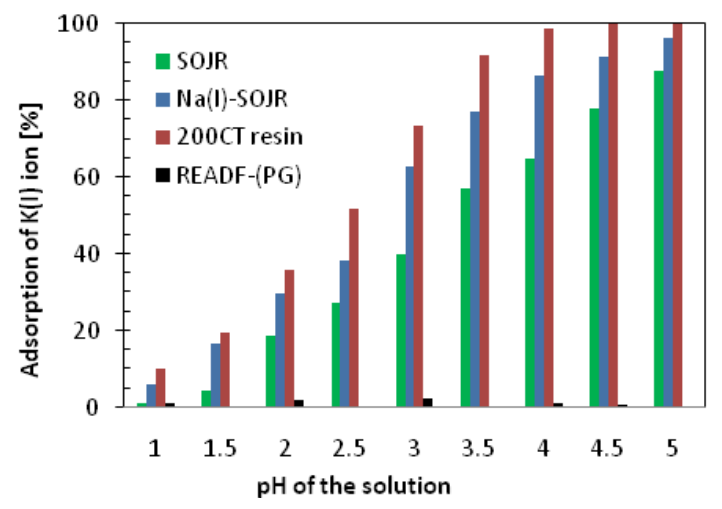

Figure 3: Adsorption of K(I) ion from leached liquor of $I A C D$ using different types of adsorbents leach liquor. The exchange of monovalent $\mathrm{Na}(\mathrm{I})$ is energetically more favored than divalent $\mathrm{Ca}$ (II) during the adsorption process so that $\mathrm{Na}(\mathrm{I})-\mathrm{SOJR}$ and 200CT more effective for the adsorption of K(I) than SOJR by cation exchange mechanism (Scheme 2). 200CT is a commercially available cation exchange resin which is synthesized by series of a chemical reaction using different chemicals. On the other hand, the synthetic route of $\mathrm{Na}(\mathrm{I})$-SOJR is very simple and low cost because the feed material for this adsorbent is orange waste itself. Therefore, the application of $\mathrm{Na}(\mathrm{I})-\mathrm{SOJR}$ investigated in this study can be used as an alternative material for the recovery of $\mathrm{K}(\mathrm{I})$ from the leach liquor of IACD. A similar observation was reported by Paudyal et al. 2020 for the adsorption of rare earth metals onto SOJR adsorbent [22].

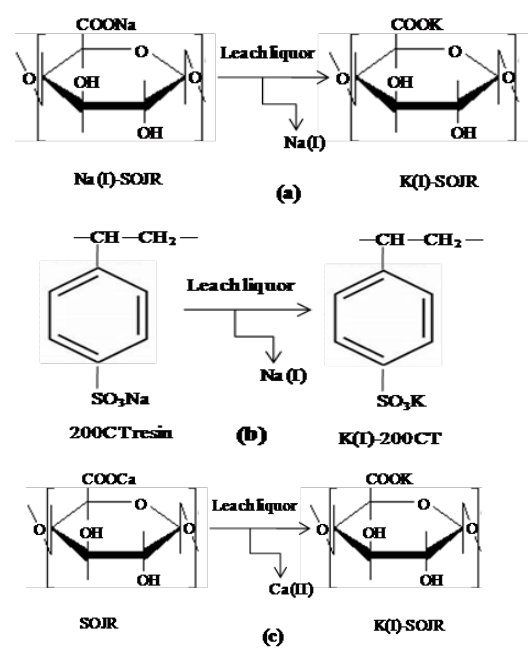

Scheme 2: Mechanism of $K(I)$ adsorption from leach liquor of IACD onto (a) Na(I)-SOJR, (b) 200CT resin, and (c) SOJR adsorbents by the cation exchange mechanism

\section{Desorption of K(I) from K(I)-SOJR using $\mathrm{H}_{2} \mathrm{SO}_{4}$ solution}

Since $\mathrm{Na}(\mathrm{I})-\mathrm{SOJR}$ was found to be equally effective for the adsorption of $\mathrm{K}(\mathrm{I})$ (earlier section) compared with commercially available cation exchange resin containing exchangeable $\mathrm{Na}(\mathrm{I})$ ion so the desorption experiment was carried out only using $\mathrm{Na}(\mathrm{I})-\mathrm{SOJR}$. Before the desorption test, $\mathrm{K}$ (I) adsorbed $\mathrm{Na}$ (I)-SOJR was prepared by shaking $5 \mathrm{~g}$ of $\mathrm{Na}(\mathrm{I})-\mathrm{SOJR}$ and 500 $\mathrm{mL}$ of leached liquor for $24 \mathrm{~h}$ at $\mathrm{pH} 4$. After filtration, it was filtered washed, and dried, which is termed as $\mathrm{K}(\mathrm{I})$-SOJR. The preliminary desorption experiment of $\mathrm{K}(\mathrm{I})$ was carried out by using $\mathrm{NaOH}, \mathrm{NaCl}$, and $\mathrm{H}_{2} \mathrm{SO}_{4}\left(1 \mathrm{M}\right.$ each), from which $1 \mathrm{M} \mathrm{H}_{2} \mathrm{SO}_{4}$ was found to be effective among three desorbing solutions. Therefore, a further desorption experiment was 
performed by using a varying concentration of $\mathrm{H}_{2} \mathrm{SO}_{4}$ and the result is shown in Fig. 4.

The result shows that the desorption of $\mathrm{K}(\mathrm{I})$ increased with increasing $\mathrm{H}_{2} \mathrm{SO}_{4}$ concentration at lower

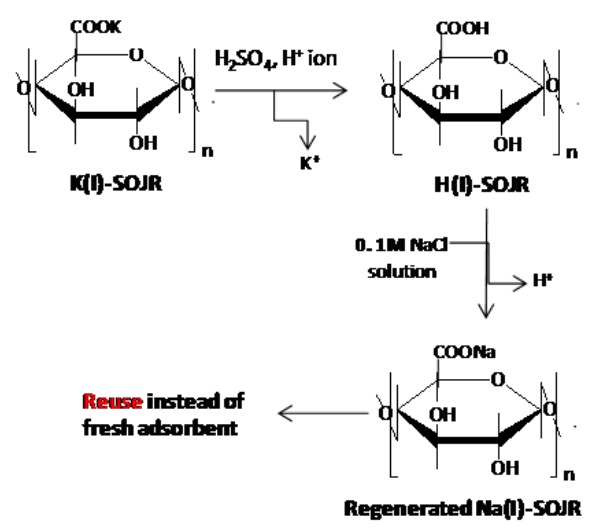

Scheme 3: Desorption of K(I) from K(I)-SOJR by $\mathrm{H}_{2} \mathrm{SO}_{4}$ and adsorbent regeneration by $\mathrm{NaCl}$ for further usage

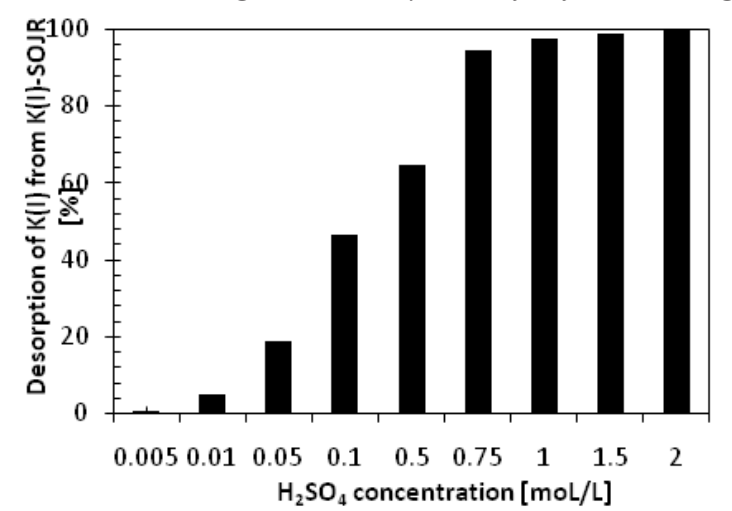

Figure 4: Desorption of adsorbed K(I) from K(I)-SOJR by using a varying concentration of $\mathrm{H}_{2} \mathrm{SO}_{4}$ solution

concentrationregion whereasitwas found to be constant or attains plateau value at higher concentration. The leaching of $\mathrm{K}(\mathrm{I})$ was only $0.56 \%$ by using $0.005 \mathrm{M}$ $\mathrm{H}_{2} \mathrm{SO}_{4}$ and it was increased to $46.29 \%$ by increasing $\mathrm{H}_{2} \mathrm{SO}_{4}$ concentration from 0.005 to $0.1 \mathrm{M}$ but $0.75 \mathrm{M}$ $\mathrm{H}_{2} \mathrm{SO}_{4}$ is required to desorbed $95 \%$ of $\mathrm{K}(\mathrm{I})$ from $\mathrm{K}(\mathrm{I})-\mathrm{SOJR}$. The desorption of K(I) becomes nearly constant or not increased significantly with further increasing of acid concentration. Therefore, $0.75 \mathrm{M}$ $\mathrm{H}_{2} \mathrm{SO}_{4}$ solution is optimized for effective desorption of adsorbed potassium from K(I)-SOJR. It is inferred that the adsorbed potassium from K(I)-SOJR was an exchange with a proton $\left(\mathrm{H}^{+}\right)$supplied from desorbing solution $\left(\mathrm{H}_{2} \mathrm{SO}_{4}\right.$ acid) by cation exchange mechanism according to the reaction shown below Scheme 3 . After desorption, the adsorbent can be regenerated by treating it with $\mathrm{NaCl}$ solution after washing for reuse instead of the fresh adsorbent.

\section{Conclusions}

It is concluded from this study that $\mathrm{H}_{2} \mathrm{SO}_{4}$ leaching followed by adsorption onto $\mathrm{Na}(\mathrm{I})$-SOJR is a very good option for the recovery of K(I) from IACD. READF-(PG) hardly adsorbs $\mathrm{K}(\mathrm{I})$ ion whereas $\mathrm{Na}(\mathrm{I})$ SOJR shows good potential for the removal of K(I) from leach liquor. Efficient leaching of $\mathrm{K}(\mathrm{I})$ from IACD was achieved using a $1 \mathrm{M} \mathrm{H}_{2} \mathrm{SO}_{4}$ solution. $\mathrm{Na}(\mathrm{I})-\mathrm{SOJR}$ adsorbent prepared from orange waste was successfully adsorbed $98.68 \%$ of $\mathrm{K}(\mathrm{I})$ from leached liquor of IACD at $\mathrm{pH} 4$. It is inferred that the adsorption mechanism occurs through a cation exchange reaction between the $\mathrm{K}(\mathrm{I})$ ion from IACD leached liquor and $\mathrm{Na}(\mathrm{I})$ ions from $\mathrm{Na}(\mathrm{I})-\mathrm{SOJR}$ and 200CT resin. Adsorbed K(I) from K(I)-SOJR was successfully desorbed in a high concentration using a $0.75 \mathrm{M} \mathrm{H}_{2} \mathrm{SO}_{4}$ solution. The concentrated solution of potassium is suitable for the effective precipitation of desorbed $\mathrm{K}(\mathrm{I})$ as a useful material. Therefore, the leaching of IACD by $\mathrm{H}_{2} \mathrm{SO}_{4}$ solution followed by adsorption using orange waste gel can be a promising technology for the recovery of $\mathrm{K}(\mathrm{I})$ from leach liquor of IACD.

\section{Acknowledgments}

The authors of this paper are thankful to NANGOKUKOSAN Co. Ltd., Miyazaki, Japan, and JA. Saga Beverage Co. Ltd., Japan for providing IACD sample and orange waste employed in this study free of cost. Nihon Kaisui Co. Ltd., Tokyo, Japan, and ORGANO Corporation, Tokyo, Japan are also heartily acknowledged for providing READF resin (READF-(PG)) and 200CT resin, respectively.

\section{References}

1. S. Petzet, B. Peplinski, S.Y. Bodkhe and P. Cornel, Recovery of phosphorus and aluminum from sewage sludge ash by a new wet chemical elution process (SESAL-Phos-recovery process), Water Science and Technology, 2011, 64, 693-699. https://doi.org/10.2166/wst.2011.682

2. J.O. Azeez and W.V. Averbeke, Fate of manure phosphorus in a weathered sandy clay loam soil amended with three animal manures, Bioresource Technology, 2010, 101, 6584 - 6588. https://doi. org/10.1016/j.biortech.2010.03.073

3. K. Kaikake, T. Sekito and Y. Dote, Phosphate recovery from the phosphorus-rich solution obtained from chicken manure incineration ash, Waste Management, 2009, 29, 1084-1088. https://doi.org/10.1016/j.wasman.2008.09.008

4. H. Paudyal, K. Inoue, K. Ohto, H. Kawakita and H. Harada, Recovery of phosphorus from 
incineration ash of chicken dropping by citric acid leaching followed by adsorption using a porous resin containing hydrated zirconium oxide powder, Journal of Chemical Engineering of Japan, 2019, 52(5), 465-470. https://doi. org/10.1252/jcej.18we252

5. Y. Kalmykova, R. Harder, H. Borgestedt and I. Svanäng, Pathways and management of phosphorus in urban areas, Journal of Industrial Ecology, 2012, 6, 928 - 939.

6. C. Ott and H. Rechberger, The European phosphorus balance, Resources Conservation and Recycling, 2012, 60, 159-172. https://doi.org/10.1016/j. resconrec.2011.12.007

7. T. Yanagidaa, T. Minowa, Y. Shimizu, Y. Matsumura and Y. Noda, Recovery of activated carbon catalyst, calcium, nitrogen and phosphate from effluent following supercritical water gasification of poultry manure, Bioresource Technology, 2009, 100, 4884-4886. https://doi.org/10.1016/j. biortech.2009.05.042

8. A. Nakamura, E. Kiyonaga, Y. Yamamura, Y. Shimizu, T. Minowa, Y. Noda and Y. Matsumura, Catalyst-suspended chicken manure gasification in supercritical water, Journal of Chemical Engineering of Japan, 2008, 41, 433-440. https:// doi.org/10.1252/jcej.07WE289

9. S.K. Jena, N. Dhawan, D.S. Rao, P.K. Misra, B.K. Mishra, B. Das, Studies on extraction of potassium values from nepheline syenite, International Journal of Mineral Processing, 2014, 133, 13-22.

10. D. Ciceri, D.A. Manning, A. Allanore, Historical and technical developments of potassium resources, Science of Total Environment, 2015, 502, 590-601. https://doi.org/10.1016/j. scitotenv.2014.09.013

11. D. Ciceri, M. de Oliveira, D.P. Chen, A. Allanore, Role of processing temperature and time on the hydrothermal alteration of $\mathrm{K}$-feldspar rock in autoclave, Mining Metallurgy and Exploration, 2020, 37, 955-963. https://doi.org/10.1007/ s42461-020-00233-6

12. J. Ma, S. Zhang, R. Lv, W. Wang, Y. Qin, C. Wang, The leaching kinetics and mechanism of potassium from phosphorus-potassium associated ore in hydrochloric acid at low temperature, Separation Science and Technology, 2017, 52, 132-141. https://doi.org/10.1080/01496395.201 6.1250776

13. D. Ciceri, M. de Oliveira, A. Allanore, Potassium fertilizer via hydrothermal alteration of K-feldspar ore, Green Chemistry, 2017, 19, 5187-5202. https://doi.org/10.1039/C7GC02633A

14. Z. Luo, J. Yang, H. Ma, M. Liu, X. Ma, Recovery of magnesium and potassium from biotite by sulfuric acid leaching and alkali precipitation with ammonia, Hydrometallurgy, 2015, 157, 188-193. http://dx.doi.org/10.1016/j. hydromet.2015.08.018

15. B.K. Biswas, K. Inoue, H. Hiroyuki, K. Ohto and H. Kawakita, Leaching of phosphorus from incinerated sewage sludge ash by means of acid extraction followed by adsorption on orange waste gel, Journal of Environmental Science, 2009, 21, 1753 -1760. https://doi.org/10.1016/ S1001-0742(08)62484-5

16. H. Paudyal, B. Pangeni, K. Inoue, H. Kawakita, K. Ohto, H. Harada and S. Alam, Adsorptive removal of fluoride from water using orange waste loaded with multi-valent metal ions, Journal of Hazardous Materials, 2011, 192, 676 - 682. https://doi.org/10.1016/j.jhazmat.2011.05.070

17. H. Paudyal, B. Pangeni, K. Inoue, M. Matsuada, R. Suzuki, H. Kawakita, K. Ohto, B.K. Biswas and S. Alam, Adsorptive behavior of fluoride ion on $\mathrm{Zr}$ (IV) loaded orange waste gel from aqueous solution, Separation Science and Technology, 2012, 47, 96-103. https://doi.org/10.1080/014963 95.2011.607204

18. H. Paudyal, B. Pangani, K. Inoue, H. Kawakita, K. Ohto and S. Alam, Removal of fluoride from aqueous solution by using porous resin containing hydrated oxide of cerium(IV) and zirconium(IV), Journal of Chemical Engineering of Japan, 2012, 45(5), 331-336. https://doi.org/10.1252/ jcej.11we181

19. P. L. Homagai, H. Paudyal, K. N. Ghimire, Adsorption kinetics of $\mathrm{Pb}(\mathrm{II}), \mathrm{Cd}(\mathrm{II}), \mathrm{Zn}$ (II) and $\mathrm{Fe}(\mathrm{III})$ onto saponified apple waste, Journal of Nepal Chemical Society, 2008, 23, 102105. https://doi.org/10.3126/jncs.v23i0.2103

20. M. Ozdemir, D. Cakir, I. Kipcak, Magnesium recovery from magnesite tailings by acid leaching and production of magnesium chloride hexahydrate from leaching solution by evaporation, International Journal of Mineral Processing, 2009, 93(2), 209-212. https://doi.org/10.1016/j.minpro.2009.08.001

21. C.E. Harvie, N. Moller, J.H. Weare, The prediction of mineral solubilities in natural waters: the Na$\mathrm{K}-\mathrm{Mg}-\mathrm{Ca}-\mathrm{H}-\mathrm{Cl}-\mathrm{SO}_{4}-\mathrm{OH}-\mathrm{HCO}_{3}-\mathrm{CO}_{3}-\mathrm{CO}_{2}-\mathrm{H}_{2} \mathrm{O}$ system to high ionic strengths at $25^{\circ} \mathrm{C}$, Geochimca et Cosmochimica Acta, 1984, 48(4), 723 -751. https://doi.org/10.1016/0016-7037(84)90098-X

22. H. Paudyal, B. Pangani, K.N. Ghimire, K. Inoue, K. Ohto, H. Kawakita, and S. Alam, Adsorption behavior of orange waste gel for some rare-earth ions and its application to the removal of fluoride from water, Chemical Engineering Journal, 2012, 195-196, 289-296. https://doi.org/10.1016/j. cej.2012.04.061 